\title{
Envisager la retraite avec sérénité
}

Avez-vous connaissance des prestations qui vous seront dues à la retraite? Avez-vous calculé la possibilité d'une retraite anticipée? Lors de votre planification de retraite nous vous indiquons comment vous pouvez financer de manière optimale votre $3^{\text {ème }}$ âge. Nous calculons les prestations de vos assurances sociales et de la prévoyance professionnelle et vous indiquons dans quelle mesure vous pouvez optimiser vos impôts. Ensemble nous établissons un concept afin de vous permettre de prévoir l'avenir avec sérénité.

\section{Etes-vous sûr?}

$\square$ J'aimerais pouvoir me réjouir de la retraite et souhaite donc me faire conseiller. Veuillez me contacter par téléphone.

\section{Prénom / Nom}

Adresse

NPA/Lieu

Date de naissance

Téléphone privé / cabinet

Atteignable le plus facilement

Adresse E-Mail

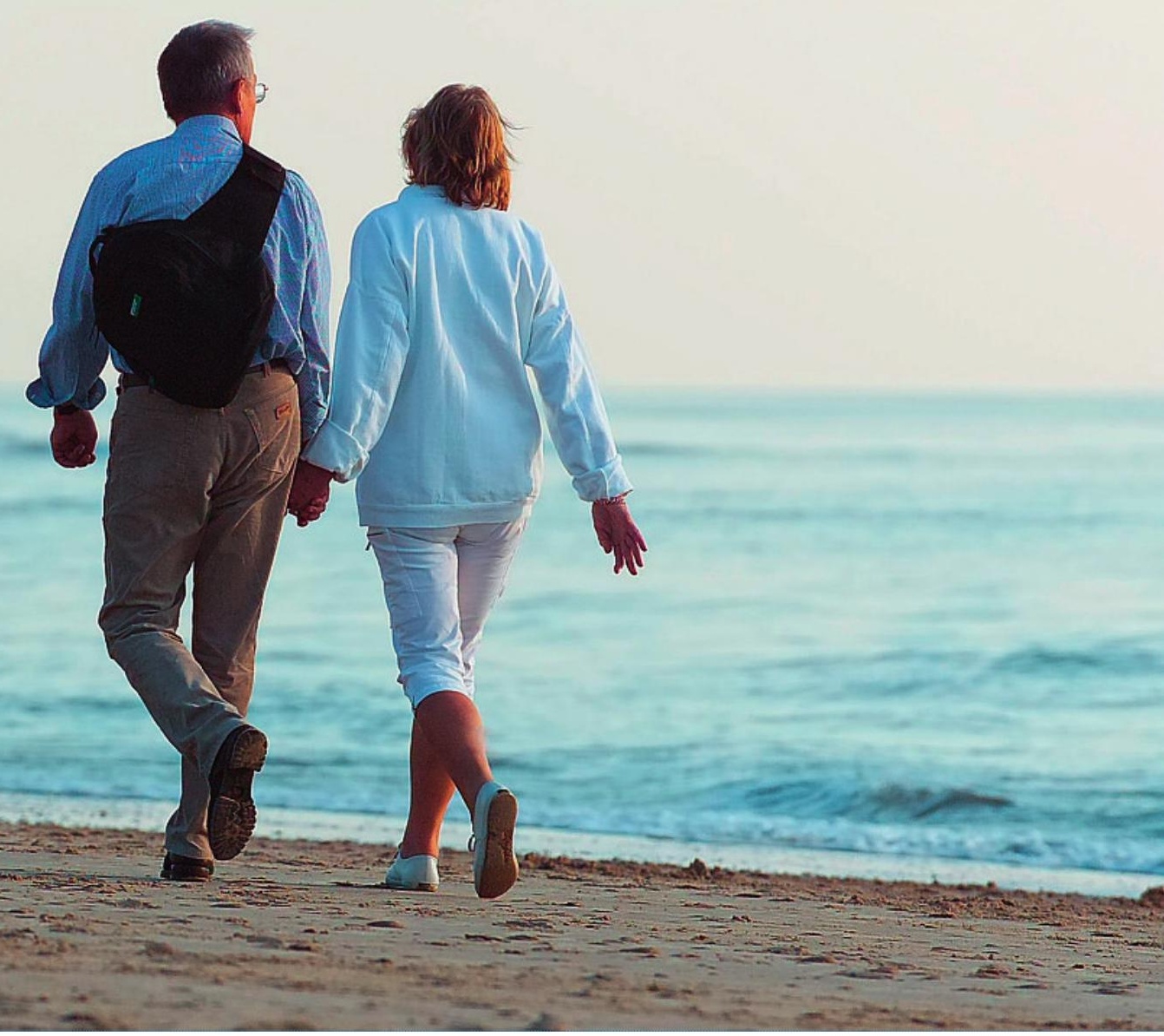

